\title{
Lacrimal Gland Squamous Cell Carcinoma
}

National Cancer Institute

\section{Source}

National Cancer Institute. Lacrimal Gland Squamous Cell Carcinoma. NCI Thesaurus.

Code C6092.

A squamous cell carcinoma that arises from the lacrimal gland. 